\title{
SALES AND PURCHASE OF WEBSITE BASED HEAVY EQUIPMENT SPAREPART
}

Rabiatul Adwiya ${ }^{1}$, Nanda Diaz Arizona $^{2}$, Yulia $^{3}$, M. Rio Pambudi ${ }^{4}$

Universitas Bina Sarana Informatika

Jalan Abdul Rahman Saleh No.A-18, Pontianak, Kalimantan Barat 78112

e-mail: $^{\text {rabiatul.rba@bsi.ac.id }}{ }^{2}$ nanda.ndz@bsi.ac.id ${ }^{3}$ yulia.yla@bsi.ac.id

$\underline{{ }^{4} \text { riopambudi@gmail.com }}$

\begin{abstract}
ABSTRAK-Membahas tentang perancangan sistem informasi Penjualan dan pembelian sparepart Pada PT. Meta Estetika Graha (MEG) adalah perusahaan yang melakukan jasa konstruksi untuk proyek perkebunan dengan skala kecil sampai menengah. Sistem ini dirancang menggunakan bahasa pemograman hyper text preprocessor (PHP) dan hyper text markup language (HTML) sebagai web editor. MySQL sebagai basis data dan Xampp sebagai web server. Metode yang digunakan pada pengembangan perangkat lunak ini menggunakan model waterfall atau yang sering disebut metode air terjun dan teknik pengumpulan data yang digunakan yaitu pengamatan langsung (observasi), wawancara (interview) serta studi pustaka. Dengan adanya sistem rancangan ini diharapkan dapat menyelesaikan sebuah sistem informasi penjualan dan pembelian sparepart alat berat berbasis website. Dengan begitu proses penjualan dan pembelian sparepart alat berat dapat dilakukan dengan cepat dan mudah selain itu data-data tidak mudah hancur dan hilang.
\end{abstract}

\section{Kata kunci: sparepart, penjualan dan pembelian}

ABSTRACT-Discussing about the design of information systems Sales and purchase of spare parts at PT. Meta Aesthetic Graha (MEG) is a company that performs construction services for small to medium scale plantation projects. This system is designed using the hyper text preprocessor (PHP) programming language and hyper text markup language (HTML) as a web editor. MySQL as a database and Xampp as a web server. The method used in the development of this software uses the waterfall model or often called the waterfall method and the data collection techniques used are direct observation (interview), interview (interview) and literature study. With this design system, it is expected to complete a websitebased sales and purchase information system for heavy equipment spare parts. That way the process of selling and buying heavy equipment spare parts can be done quickly and easily besides the data that is not easily destroyed and lost

Keywords: sparepart, sales and purchase 

Adwiya, Rabiatul (2019) 



\section{PENDAHULUAN}

Suatu perusahaan dalam pelayanan penjualan dan pembelian kepada masyarakat sudah harus menggunakan teknologi informasi yang canggih untuk mempermudah sekaligus mempercepat aktivitas pekerjaan, terutama dalam proses penjualan dan pembelian barang. Pemilik perusahaan sudah harus memikirkan bagaimana proses penjualan dan pembelian dengan cara yang lebih efektif agar tidak memakan waktu yang cukup lama dan juga dapat meminimalisir kesalahan dalam proses penjualan dan pembelian barang, jawabannya dengan memanfaatkan teknologi yang sudah terkomputerisasi. Penjualan dan pembelian merupakan kegiatan yang dapat mempengaruhi jumlah persediaan. Informasi yang dihasilkan akan membantu pemilik dalam memutuskan jumlah persediaan yang akan dibeli, maupun jumlah yang tersedia untuk dijual, serta mengontrol dan mengawasi jumlah asset persediaan.

Salah satu perusahaan yang membutuhkan kegiatan penjualan dan pembelian secara sistem yang sudah terkomputerisasi adalah PT. Meta Estetika Graha (MEG). PT Meta Estetika Graha bergerak dibidang perdagangan untuk penjualan alat berat dan suku cadang (sparepart). Alat berat tersebut pasti membutuhkan penggantian suku cadang (sparepart) secara berkala ataupun penggantian karena rusak demi memperoleh performa yang maksimal. Dalam melakukan penjualan dan pembelian sparepart alat berat PT. Meta Estetika Graha masih melakukan pendataan penjualan dan pembelian secara manual atau tulis tangan, sedangkan untuk mengolah data-data laporan penjualan dan pembelian sparepart alat berat tersebut, karyawan hanya menggunakan aplikasi Microsoft Excel dimana belum menggunakan suatu sistem informasi akuntasi yang telah terkomputerisasi. Dengan cara tersebut terdapat beberapa kekurangan yaitu dapat terjadi kesalahan dalam penulisan dan pembacaan, tidak ringkas, lamanya proses pelayanan kepada pembeli, dokumen yang rentan hilang dan rusak, dan tempat penyimpanan yang terbatas.

Adapun permasalah pada penelitian ini adalah bagaimana membuat sistem informasi akuntansi penjualan dan pembelian sparepart alat berat berbasis website. Dengan begitu proses penjualan dan pembelian sparepart alat berat dapat dilakukan dengan cepat dan mudah, selain itu data-data tidak mudah hancur dan hilang. PT Meta Estetika Graha juga akan mampu bersaing dengan perusahaan yang lainnya dan memberikan pelayanan terbaik untuk masyarakat yang membutuhkan sparepart alat berat. Dengan website ini diharapkan dapat membantu proses pelayanan dalam bagian penjualan dan juga memudahkan bagi para karyawan dalam menyusun laporan penjualan sparepart alat berat pada PT. Meta Estetika Graha.

\section{METODOLOGI PENELITIAN}

Metode penelitian dan teknik pengumpulan data yang digunakan untuk dalam penelitian ini adalah :

\section{Metode \\ Perangkat Lunak}

Metode yang digunakan pada pengembangan perangkat lunak ini menggunakan model prototype yang terbagi menjadi tiga tahapan, yaitu :

a. Pengumpulan Kebutuhan

Pada tahapan pengumpulan kebutuhan, penulis bertemu dengan pihak perusahaan untuk mendengarkan keluhan permasalahan mengenai sistem penjualan dan pembelian alat berat untuk menciptakan gambaran suatu sistem yang dibutuhkan.

b. Rancangan Prototype 
Pada tahapan rancangan prototipe ini, penulis melakukan perancangan dan pembuatan prototipe sistem menggunakan bahasa pemrograman HTML dan PHP, menggunakan aplikasi XAMPP, menggunakan MySql sebagai basis data serta phpMyAdmin sebagai media database. Prototipe yang dibuat disesuaikan dengan pengumpulan kebutuhan.

c. Evaluasi Prototype

Pada tahapan evaluasi prototipe ini, penulis dan pihak perusahaan mengkaji ulang prototipe sistem yang telah dibuat dan memperdalam sistem tersebut untuk menemukan kekurangan sehingga dapat diperbaiki.

2. Teknik Pengumpulan Data

Teknik pengumpulan data yang digunakan dalam melakukan pengumpulan data untuk penelitian adalah :

a. Observasi

Melalui metode ini penulis melakukan pengamatan langsung pada PT. Meta Estetika Graha mengenai sistem penjualan dan pembelian alat berat yang ada pada perusahaan tersebut.

Tabel 1. Jadwal Implementasi

\begin{tabular}{|c|c|c|c|c|c|c|c|c|c|c|c|c|c|}
\hline \multirow{3}{*}{$\begin{array}{l}\mathrm{N} \\
\mathrm{O}\end{array}$} & \multirow{3}{*}{ Tahapan Kegiatan } & \multicolumn{12}{|c|}{ Waktu Kegiatan } \\
\hline & & \multicolumn{4}{|c|}{ Mei } & \multicolumn{4}{|c|}{ Juni } & \multicolumn{4}{|c|}{ Juli } \\
\hline & & 1 & 2 & 3 & 4 & 1 & 2 & 3 & 4 & 1 & 2 & 3 & 4 \\
\hline 1 & Riset & & & & & & & & & & & & \\
\hline 2 & Analisa Kebutuhan & & & & & & & & & & & & \\
\hline 3 & Analisa Sistem Berjalan & & & & & & & & & & & & \\
\hline 4 & Evaluasi & & & & & & & & & & & & \\
\hline
\end{tabular}

Sumber : Hasil Penelitian (2019)

\section{HASIL DAN PEMBAHASAN}

1. Prosedur Sistem Berjalan

Dalam penelitian ini prosedur sistem berjalan yang diamati adalah prosedur penjualan dan pembelian sparepart alat berat pada PT. Meta b. Wawancara

Dalam metode ini penulis mengumpulkan data dengan cara melakukan tanya jawab langsung ke pada bagian manager bapak Yohanes Maka luas operasional PT. MEG. Penulis melakukan wawancara mengenai prosedur penjualan dan pembelian alat berat yang ada pada PT Meta Estetika Graha

c. Studi Pustaka

Dalam metode ini penulis mencari data dari buku-buku dan jurnal penelitian dan buku-buku yang berhubungan dengan studi literatur pada buku atau referensi yang berkaitan dengan pembuatan aplikasi dan artikel-artikel penunjang yang didapatkan dari internet.

\section{Implementasi}

Dalam usaha untuk membangun sebuah sistem, diperlukan tahapantahapan agar sistem yang dirancang dapat dibuat dengan semestinya. Pengimplementasian dari sistem ini membutuhkan waktu selama 3 bulan adapun rincian kegiatan sebagai berikut: 
Konsumen datang langsung ke perusahaan untuk melihat dan memilih sparepart yang diinginkan.

b. Prosedur pengecekkan sparepart

Setelah kasir menerima pesanan dari konsumen, kemudian kasir mengecek sparepart yang di inginkan oleh konsumen serta memberikan harga onderdil yang diinginkan oleh konsumen.

Kemudian kasir membuat nota penjualan kepada konsumen untuk di berikan kepada bagian unit.

c. Prosedur pengambilan sparepart Apabila bagian unit telah menerima nota maka bagian unit akan mengambilkan onderdil yang telah diinginkan oleh konsumen. Kemudian sparepart yang di inginkan oleh konsumen di berikan ke pada kasir untuk melakukan pembayaran.
Pada proses pembayaran, konsumen datang ke kasir untuk melakukan pembayaran dan mengambil pesanan sparepart yang telah di pesan.

e. Laporan akhir

Pada proses laporan, bagian unit membuat data-data barang habis terjual kepada bagian bagian marketing. Bagian marketing membuat rekapan laporan harian untuk nantinya disatukan dan dijadikan laporan akhir bulan.

Dari hasil riset yang dilakukan pada PT. Meta Estetika Graha dapat diketahui bentuk sistem secara garis besar yang berjalan pada PT. Meta Estetika Graha. Berikut gambar 1 ini merupakan bentuk Activity Diagram dari sistem yang dijalankan pada PT. Meta Estetika Graha.

d. Prosedur pembayaran

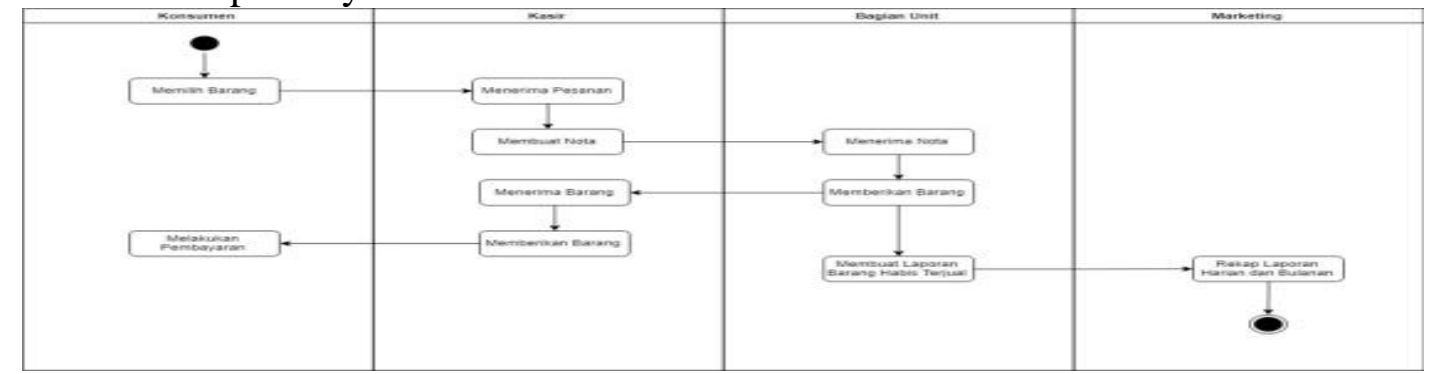

Sumber : Hasil Penelitian 2019

Gambar 1. Activity Diagram Proses Sistem Berjalan

\section{Analisa Kebutuhan Software}

Analisa kebutuhan software dibuat untuk memudahkan penulis dalam mengetahui kebutuhan PT. Meta Estetika Graha dalam menjalani kegiatan proses kinerja yang terjadi. Dengan merancang software yang tepat untuk di implementasikan dalam sebuah project maka akan membantu juga dalam memecahkan permasalahan perusahaan. Adapun sesungguhnya dalam proses perancangan ini merupakan bentuk dari perancangan sistem yang manual ke sistem yang terkomputerisasi yang akan digunakan dalam sebuah program komputer dengan mengetahui dasar yang ada dibutuhkan juga konfigurasi sistem yang terkomputerisasi untuk mengetahui kapasitas yang tepat dalam haedware dan software yang digunakan. Sehingga tujuan dari sebuah perancangan sistem dapat dihasilkan yaitu memudahkan penggunanya dalam menjalani proses bisnis pada perusahaan.

\section{Use Case Diagram}

Diagram ini menunjukan fungsionalitas suatu sistem atau kelas dari bagaimana sistem berintraksi dengan dunia luar. Perancangan proses yang diusulkan dalam sitem informasi 
penjualan dan pembelian sebagai berikut

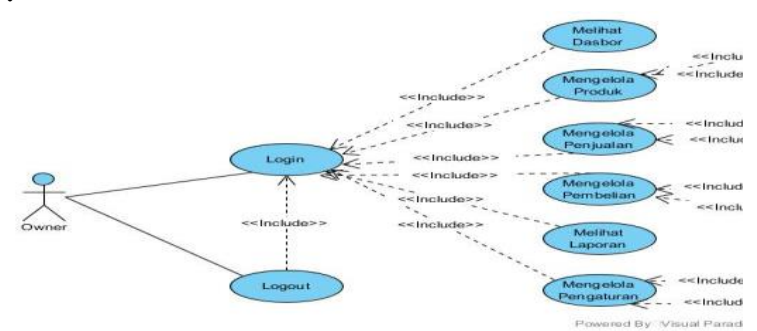

Sumber : Hasil Perancangan (2019)

Gambar 2. Use Case Diagram

\section{Tabel 2}

Use Case Deskripsi Halaman Admin

\begin{tabular}{|l|l|}
\hline Deskripsi Use Case Diagram Halaman Admin \\
\hline Tujuan & $\begin{array}{l}\text { Owner dapat melakukan } \\
\text { pengolahan data yang ada di } \\
\text { menu penjualan dan menu } \\
\text { Pembelian serta melihat } \\
\text { Beranda dan melihat menu } \\
\text { Laporan. }\end{array}$ \\
\hline Deskripsi & $\begin{array}{l}\text { Pada Sistem ini Aktor dapat } \\
\text { mengelola menu di Manajemen } \\
\text { Data meliputi data produk, } \\
\text { kategori, penjualan dan menu } \\
\text { pembelian. Owner dapat } \\
\text { melihat menu laporan yang } \\
\text { meliputi laporan Penjualan dan } \\
\text { Pembelian. }\end{array}$ \\
\hline $\begin{array}{l}\text { Aktor } \\
\text { Owner }\end{array}$ \\
\hline Skenario Utama \\
Kwal & Owner telah berhasil Login \\
\hline Aksi Aktor & Reaksi Sistem \\
\hline $\begin{array}{l}\text { Owner } \\
\text { menu Dasbor }\end{array}$ & $\begin{array}{l}\text { Sistem menampilkan } \\
\text { halaman Dasbor }\end{array}$ \\
\hline $\begin{array}{l}\text { Owner } \\
\text { menu Produk }\end{array}$ & $\begin{array}{l}\text { Sistem menampilkan } \\
\text { sub menu : } \\
\text { Produk }\end{array}$ \\
\hline
\end{tabular}

\begin{tabular}{|l|l|}
\hline $\begin{array}{l}\text { Owner memilih } \\
\text { menu Penjualan }\end{array}$ & $\begin{array}{l}\text { Sistem menampilkan } \\
\text { sub menu : } \\
\text { Penjualan } \\
\text { Pelanggan }\end{array}$ \\
\hline $\begin{array}{l}\text { Owner memilih } \\
\text { menu Pembelian }\end{array}$ & $\begin{array}{l}\text { Sistem menampilkan } \\
\text { sub menu : } \\
\text { Pembelian } \\
\text { Penyuplai }\end{array}$ \\
\hline $\begin{array}{l}\text { Owner memilih } \\
\text { menu Laporan }\end{array}$ & $\begin{array}{l}\text { Sistem menampilkan } \\
\text { halaman Laporan }\end{array}$ \\
\hline $\begin{array}{l}\text { Owner memilih } \\
\text { menu Pengaturan }\end{array}$ & $\begin{array}{l}\text { Sistem menampilkan } \\
\text { sub menu: } \\
\text { Pengaturan } \\
\text { Kode }\end{array}$ \\
\hline $\begin{array}{l}\text { Kondisi } \\
\text { Akhir }\end{array}$ & $\begin{array}{l}\text { Jika perintah sesuai prosedur } \\
\text { maka } \\
\text { menampilkan halaman Owner }\end{array}$ \\
\hline
\end{tabular}

\section{Sumber Hasil Rancangan (2019)}

\section{Desain}

Desain merupakan tahap setelah analisa sistem dari siklus pembangunan sistem yang mendefinisikan dari kebutuhan fungsional, persiapan untuk merancang sebuah aplikasi. Berikut ini adalah desain dari sebuah sistem aplikasi Penjualan dan Pembelian pada PT. Meta Estetika Graha.

\section{a. Entitiy Relationship Diagram (ERD)}

Entity Relationship Diagram (ERD) menjelaskan hubungan antara data dalam basis data yang terdiri dari objek dasar yang mempunyai hubungan atau relasi antar objek tersebut. Berikut ini adalah sistem informasi Penjualan pada PT. Meta Estetika Graha:

Sumber : Hasil Perancangan (2019)

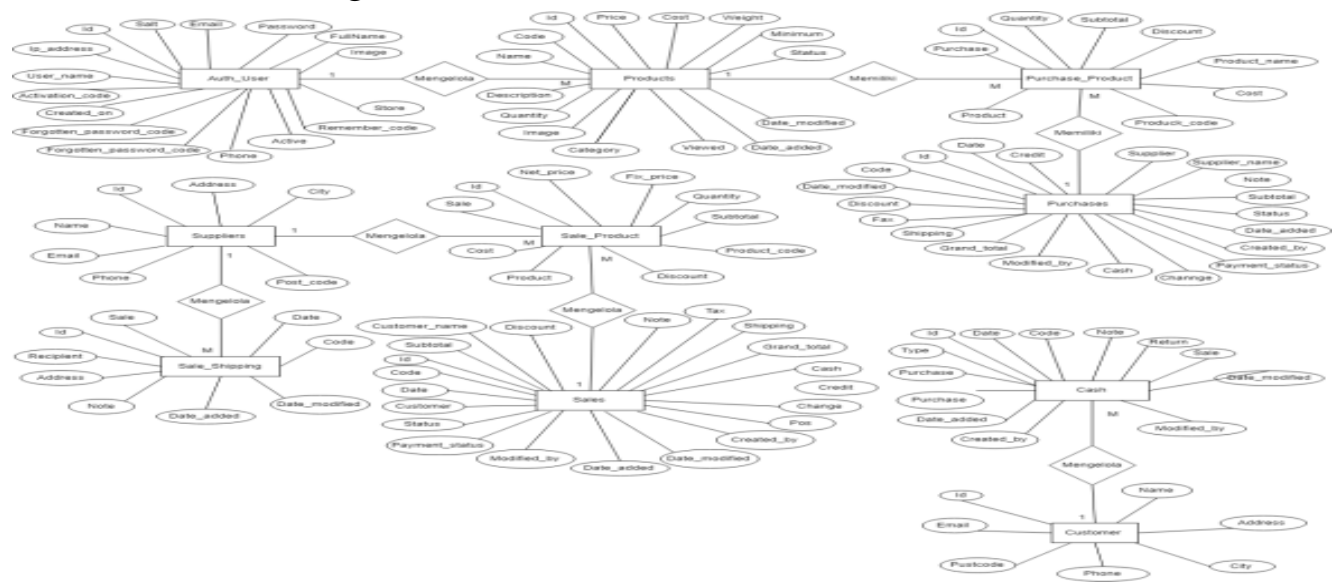

Gambar 3. Entity Relationship Diagram (ERD) 

bahwa :

Pada Gambar 3 dapat di jelaskan

1) Auth user dapat mengolah semua data produk dimana terdapat id, code, name description, quantity, image, category, price, cost, weight, minimum, status, viewed, date_added, date_modified.

2) Sales dapat mengolah data sale_product yang didalamnya terdapat id, sale, product, product_code, product_name, cost, net_price, fix_price, quantity, discount dan subtotal.

\section{b. Logical Record Structure (LRS)}

Logical Record Structure merupakan representasi dari struktur record-record pada tabel yang terbentuk dari relasi antar himpunan entitas. Relasi adalah penghubung antara satu entitas dengan entitas lain. Sistem yang ada pada Logical Record Structure adalah sebagai berikut:

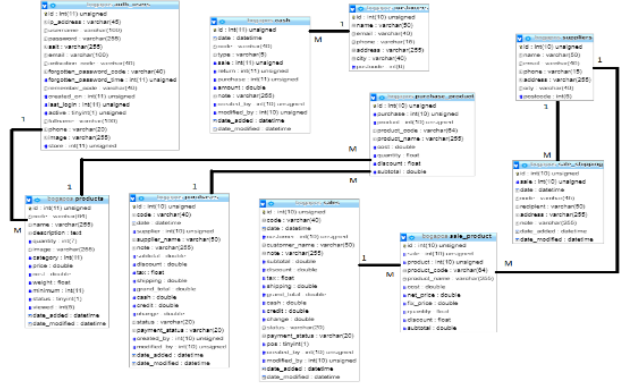

Sumber : Hasil Perancangan (2019) Gambar 4 Logical Record Structure (LRS)

Pada Gambar 4 dapat di jelaskan bahwa :

1) Auth_user dapat mengolah semua data produk dimana terdapat id, code, name description, quantity, image, category, price, cost, weight, minimum, status, viewed, date_added, date_modified.

2) Sales dapat mengolah data sale_product yang didalamnya terdapat id, sale, product, product_code, product_name, cost, net_price, fix_price, quantity, discount dan subtotal.

c. User Interface

1) Interface Halaman Admin Sparepart

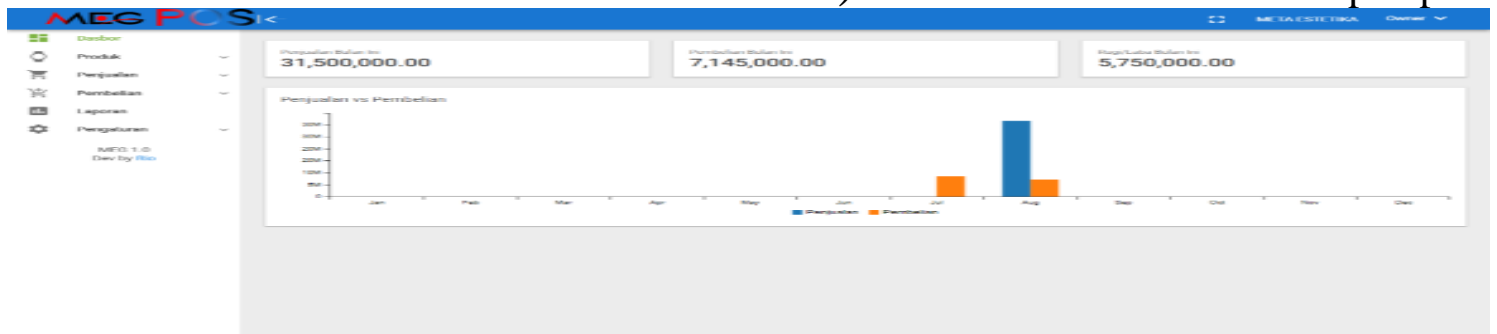

Sumber : Hasil Perancangan (2019)

Gambar 5. Interface Halaman Admin Sparepart

Nama Program $\quad$ : Menu input

Sparepart

Akronim Program : Sparepart.php

Fungsi Program : untuk

menampilkan input sparepart

Bahasa Program : HTML, PHP,

Java Script, CSS

Proses Program

a) Ketika from di jalankan, maka akan menampilkan input sparepart. b) Jika terjadi penambahan data barang baru, maka akan terdapat pilihan input sparepart.

c) Agar dapat menambah barang sparepart di menu pelanggan, sehingga pelanggan sangat puas dengan berbagai macam-macam barang.

2) Interface Halaman Admin Penjualan 



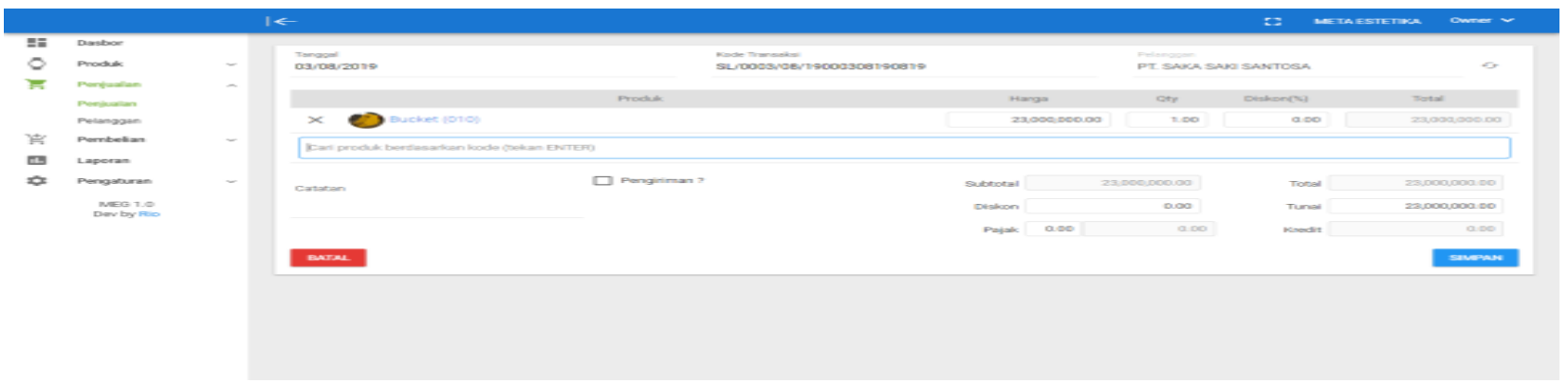

Sumber : Hasil Perancangan (2019)

Gambar 6. Interface Halaman Admin Penjualan

$\begin{array}{lcr}\begin{array}{l}\text { Nama Program } \\ \text { konfirmasi penjualan }\end{array} & \\ \begin{array}{l}\text { Akronim Program } \\ \text { penjualan.php }\end{array} & : & \text { konfimasi } \\ \begin{array}{l}\text { Fungsi Program } \\ \text { menampilkan } \\ \text { penjualan }\end{array} & : & \text { untuk } \\ \begin{array}{l}\text { Bahasa Program } \\ \text { Java Script, CSS }\end{array} & \text { konfirmasi } \\ \text { Proses Program HTML, PHP, } & & \\ \end{array}$

a) Ketika from di jalankan, maka akan menampilkan menu konfirmasi pelanggan.

konfirmasi penjualan
b) Jika terjadi penjualan dan transaksi maka di menu penjualan ini akan mengonfirmasikan.
Fungsi Program : untuk
c) Agar dapat bisa menjaga keamanan pelanggan, dan tidak terjadi penipuan akun.
3) Interface Halaman pembelian

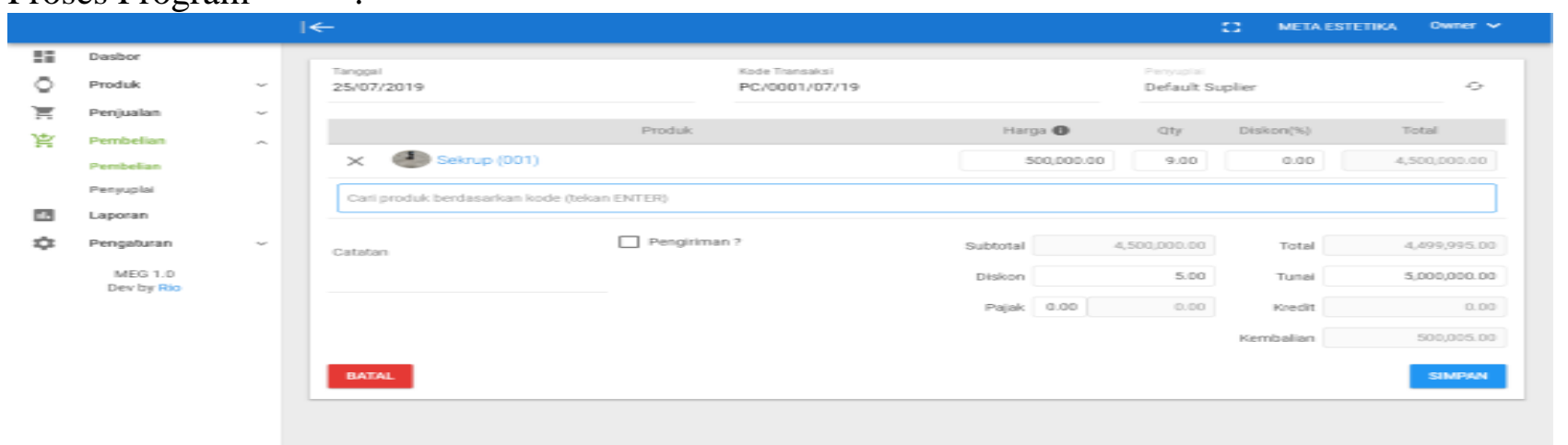

Sumber : Hasil Perancangan (2019)

Gambar 7. Interface Halaman Admin lihat akun

Nama Program : Menu pembelian

Akronim Program : adminuser.php

Fungsi Program : untuk menampilkan menu pembelian

Bahasa Program : HTML, PHP, Java Script, CSS

Proses Program :

a) Ketika from di jalankan, maka akan menampilkan menu pembelian. b) Ketika pengguna sedang beraktifitas di website penjualan maka akan terlihat tampilan pembelian.

\section{Blackbox Testing}

Black Box Testing atau pengujian adalah sebuah tindakan yang dilakukan untuk mengukur sejauh mana objek telah memenuhi sesuai harapan. Pengujian dalam Sistem Informasi Penjualan Dan Pembelian Onderdil Alat Berat Berbasis Website Pada PT. Meta Estetika Graha sebagai berikut : 
Tabel 3. Hasil Pengujian Black Box Testing Form Login

\begin{tabular}{|c|c|c|c|c|c|}
\hline No & Skenario Pengujian & Tect Case & $\begin{array}{ll}\text { Hasil } & \text { yang } \\
\text { diharapkan }\end{array}$ & $\begin{array}{l}\text { Hasil } \\
\text { pengujian }\end{array}$ & Keterangan \\
\hline 1 & $\begin{array}{l}\text { Email dan Kata Sandi } \\
\text { tidak diisi kemudian } \\
\text { klik tombol masuk }\end{array}$ & $\begin{array}{l}\text { Email } \\
\text { Pengguna } \\
\text { (kosong), Kata } \\
\text { Sandi (kosong) } \\
\end{array}$ & $\begin{array}{l}\text { Menampilkan } \\
\text { pesan "Please fill } \\
\text { out this field" }\end{array}$ & Sesuai Harapan & Valid \\
\hline 2 & $\begin{array}{l}\text { Email Pengguna tidak } \\
\text { diisi kemudaian klik } \\
\text { tombok masuk }\end{array}$ & $\begin{array}{l}\text { Email } \\
\text { Pengguna } \\
\text { (kosong), Kata } \\
\text { Sandi (benar) }\end{array}$ & $\begin{array}{l}\text { Menampilkan } \\
\text { pesan "Please fill } \\
\text { out this field" }\end{array}$ & Sesuai Harapan & Valid \\
\hline 3 & $\begin{array}{l}\text { Semua data masuk } \\
\text { diisi dengan benar } \\
\text { kemudian klik tombol } \\
\text { masuk }\end{array}$ & $\begin{array}{l}\text { Email } \\
\text { Pengguna } \\
\text { (benar), Kata } \\
\text { Sandi (benar) }\end{array}$ & $\begin{array}{l}\text { Langsung masuk ke } \\
\text { Menu Utama }\end{array}$ & Sesuai Harapan & Valid \\
\hline
\end{tabular}

Sumber : Hasil Perancangan (2019)

Tabel 4. Hasil Pengujian Black Box Testing Penjualan

\begin{tabular}{|c|l|l|l|l|l|}
\hline No & $\begin{array}{l}\text { Skenario } \\
\text { Pengujian }\end{array}$ & Tect Case & Hasil yang diharapkan & $\begin{array}{l}\text { Hasil } \\
\text { pengujian }\end{array}$ & Keterangan \\
\hline 1 & $\begin{array}{l}\text { Semua data } \\
\text { pemesanan } \\
\text { tidak diisi } \\
\text { kemudian klit } \\
\text { tombol simpan }\end{array}$ & $\begin{array}{l}\text { Code } \\
\text { transaksi, } \\
\text { (kosong) }\end{array}$ & $\begin{array}{l}\text { Menampilkan pesan } \\
\text { Data produk yang } \\
\text { dijual masih kosong" }\end{array}$ & $\begin{array}{l}\text { Sesuai } \\
\text { Harapan }\end{array}$ & Valid \\
\hline 2 & $\begin{array}{l}\text { Semua data } \\
\text { pemesanan diisi } \\
\text { kemudian klik } \\
\text { tombol simpan }\end{array}$ & $\begin{array}{l}\text { Kode Produk dengan } \\
\text { diisi denar) }\end{array}$ & $\begin{array}{l}\text { Menampilkan pesan } \\
\text { "Penjualan'kode } \\
\text { penjualan' berhasil } \\
\text { disimpan" Sesuai }\end{array}$ & $\begin{array}{l}\text { Harapan } \\
\text { Valid }\end{array}$ \\
\hline
\end{tabular}

Sumber : Hasil Perancangan (2019)

Tabel 5. Hasil Pengujian Black Box Testing Pembelian

\begin{tabular}{|c|l|l|l|l|l|}
\hline No & Skenario Pengujian & Tect Case & Hasil yang diharapkan & $\begin{array}{l}\text { Hasil } \\
\text { pengujian }\end{array}$ & Keterangan \\
\hline 1 & $\begin{array}{l}\text { Semua data pembelian } \\
\text { tidak diisi kemudian klit } \\
\text { tombol simpan }\end{array}$ & $\begin{array}{l}\text { Code transaksi, } \\
\text { (kosong) }\end{array}$ & $\begin{array}{l}\text { Menampilkan pesan } \\
\text { Data produk yang } \\
\text { dibeli masih kosong" }\end{array}$ & $\begin{array}{l}\text { Sesuai } \\
\text { Harapan }\end{array}$ & Valid \\
\hline 2 & $\begin{array}{l}\text { Semua data pembelian } \\
\text { diisi kemudian klik } \\
\text { tombol simpan }\end{array}$ & $\begin{array}{l}\text { Kode Produk diisi } \\
\text { dengan (benar) }\end{array}$ & $\begin{array}{l}\text { Menampilkan pesan } \\
\text { "Pembelian'kode } \\
\text { pembelian' berhasil } \\
\text { disimpan" Sesuai }\end{array}$ & Varapan & Valid \\
\hline
\end{tabular}

Sumber : Hasil Perancangan (2019)

\section{Spesifikasi Hardware dan} Software

a. Spesifikasi Hardware

Spesifikasi perangkat keras minimal yang dibutuhkan adalah sebagai berikut:

1) Server

a) $C P U$
(1) Processor
Intel $\AA$
BayTrailL $M$
Duol-
Core 2,50Ghz

(2) RAM 2,00 GB

(3) Hard Disk 500 GB

b) Mouse

c) Keyboard

d) Monitor dengan resolusi layar minimum 1024 x 768

e) Koneksi internet dengan kecepatan $2 \mathrm{Mbps}$

2) Client
a) $C P U$ 
(1) Processor AMD C-60 $A P U$ with Radeon(tm) $\mathrm{HD}$ Graphics $1.00 \mathrm{GHz}$

(2) RAM 2,00 GB

(3) Hard Disk 320 GB

b) Mouse

c) Keyboard

d) Monitor dengan resolusi layar minimum 1024 x 768

e) Koneksi internet dengan kecepatan $1 \mathrm{Mbps}$

\section{b. Spesifikasi Software}

Dalam pembuatan program ini dibutuhkan perangkat lunak sebagai berikut:

1) Server

a) Sistem operasi seperti Microsoft Windows 7 dan Windows XP.

b) Aplikasi web server seperti Xampp yang memiliki beberapa komponen, diantaranya:

(1) Aplikasi Apache Server

(2) Aplikasi MySQL Server

(3) Aplikasi PHP Server

(4) Aplikasi phpMyAdmin

2) Client
a) Sistem operasi seperti Microsoft Windows 7 dan Windows XP.
b) Aplikasi web browser seperti: Google Chrome dan Mozilla Firefox.

\section{KESIMPULAN}

1. Dengan adanya website PT.MEG Kubu Raya diharapkan akan memudahkan proses dalam proses pemesanan produk sparepart yang dilakukan oleh pelanggan dan pemasaran produk-produk yang ditawarkan kepada pelanggan lama ataupun pelanggan baru dengan tidak dibatasi oleh ruang dan waktu.

2. Penelitian ini menggunakan metode Prototype yang terdiri dari dari analisis, desain, pengkodean, pengujian dan tahap pendukung.

3. Melalui sistem informasi penjualan dan pembelian sparepart ini diharapkan dapat menjadi solusi dari permasalahan yang sering terjadi di perusahaan, sekaligus dapat menjadi sebuah keunggulan kompetitif perusahaan.

\section{REFERENSI}

[1] Ade Djohar Maturidi. Metode Penelitian Teknik Informatika. Yogyakarta : Deepublish (2014).

[2] Andre. Belajar HTML Dasar Part 1: Pengertian HTML. Yogyakarta : Gracindo. (2017).

[3] Ibrahim Ingga. Akuntansi Manajemen. Yogyakarta : Deepublish. (2017).

[4] Indrajit, Richardus Eko and Richardus. Djokopranoto. Manajemen Persediaan Barang dan Suku Cadang (Sparepart) Untuk Keperluan Perbaikan, Pemeliharaan dan Operasi. Yogyakarta: Grasindo, (2003).

[5] ND Arizona, Yulia, R. Saputra. "Aplikasi Pengolahan Data Penerimaan dan Pengeluaran Kas Pada SMK Cahaya Bangsa Kabupaten Kubu Raya." Pilar Nusa Mandiri (2018): 253-260. document.

[6] Nurhadi, A., Indrayuni, E., \& Sinnun, A Acmad. Perancangan Website Sistem Informasi Penjualan Kamera. Konferensi Nasional Ilmu Sosial \& Teknologi (KNiST), 205-213. (2016).

[7] Pamungkas, C. A. Dasar Pemrograman Web dengan 
PHP. Deepublish. (2017)

[8] Puji Hastanti, R., Eka Purnama, B., \& Uly Wardati, I. (2015). Sistem Penjualan Berbasis Web (E-Commerce) Pada Tata Distro Kabupaten Pacitan. Jurnal Bianglala Informatika, 3(2), 1-9. https://doi.org/10.1007/s132 26-018-0284-5

[9] Shalahuddin, Rossa dan. Rekayasa Perangkat Lunak. Bandung: Informatika Bandung, (2014).

[10] Simanjuntak, M. (2017). Perancangan Sistem Informasi Budidaya dan Penjualan Kopi Berbasis Menggunakan Php dan Mysql. Retrieved from http://repositori.usu.ac.id/ha ndle/123456789/3664

[11] Wongso, F. Perancangan Sistem Informasi Penjualan Berbasis Java Studi Kasus Pada Toko Karya Gemilang Pekanbaru. Jurnal Ilmiah Ekonomi Dan Bisnis, 12(1), 46-60. (2015). 
Jurnal Teknologi \& Manajemen Informatika - Vol.5 No.1 2019

Jurnal Teknologi \& Manajemen Informatika - Vol.5 No.1 2019 